\title{
Composição química e digestibilidade de partes e subprodutos de aves nas formas crua e cozida para cães
}

[Chemical composition and digestibility of raw and cooked chicken parts for dogs]

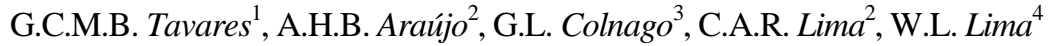 \\ ${ }^{1}$ Aluna de pós-graduação - IZ-UFRJ - Seropédica, RJ \\ ${ }^{2}$ Instituto de Zootecnia - UFRRJ - Seropédica, RJ \\ ${ }^{3}$ Faculdade de Veterinária - UFF - Niterói, RJ \\ ${ }^{4}$ Aluno de pós-graduação - IA-UFRRJ - Seropédica, RJ
}

\begin{abstract}
RESUMO
Determinou-se a composição de partes da carcaça - pescoço, dorso e pés de aves -, e sua digestibilidade, usadas para cães nas formas crua e cozida. Os animais, pesados antes e depois do período experimental, foram alimentados uma vez ao dia, com livre acesso ao alimento por uma hora. Cada animal recebeu aproximadamente $50 \mathrm{~g}$ alimento $/ \mathrm{kg}$ de peso. As fezes, coletadas diariamente, foram pesadas e congeladas até a realização das análises bromatológicas. Os pés apresentaram os maiores valores de proteína bruta (PB) e matéria mineral (MM), o pescoço, o maior valor de energia bruta (EB), e o dorso, os de matéria seca (MS), matéria orgânica (MO) e extrato etéreo (EE). O cozimento não alterou a composição dos alimentos, entretanto os alimentos cozidos apresentaram teores menores em PB e maiores em EE. Os coeficientes de digestibilidade da MO e da PB do pescoço aumentaram significativamente quando este foi cozido, e os valores de energia metabolizável (EM) e energia digestível (ED) diminuíram. O cozimento do dorso resultou em redução de EM e ED. Os coeficientes de digestibilidade da MS, MO e $\mathrm{PB}$ e a ED e EM do pé foram significativamente maiores para os pés cozidos.
\end{abstract}

Palavras-chave: cão, cozimento, digestibilidade, dorso, pé, pescoço

\begin{abstract}
In order to use an ingredient to formulate dog foods, it is ideal to the industry to know its properties including the digestibility. So, this work studied the chemical composition and the digestibility of chicken parts used to feed dogs, since they are used frequently by the dog food industry. The ingredients were raw and cooked neck, back, and feet. The animals were weighted before and after the experimental period and food was served once a day. The food was weighted before and after being served. Each animal consumed approximately $50 \mathrm{~g}$ food/kg body weight. The feces were collected daily and freezed as well as the food until the bromatological analyses procedures. The feet had the highest values for crude protein $(C P)$ and mineral content $(M C)$; while the back, the highest values for dry matter (DM), organic matter (OM), and fat. Cooking had no significant effect on chemical composition of the ingredients. Considering the digestibility coefficient, OM and CP of neck had a significant increase when it was used in the cooked form; but, the metabolizable energy $(M E)$ and the digestible energy (DE) values considerably decreased. For the back, the heat treatment resulted in a significant reduction of ME and $D E$ and the digestibility coefficients of $D M, O M$, and $C P$, and $M E$, and $D E$ of the feet were higher using the same treatment.
\end{abstract}

Keywords: dog, digestibility, chicken parts, chicken neck, chicken feet

Recebido em 5 de maio de 2009

Aceito em 25 de fevereiro de 2010

E-mail: giseletav@yahoo.com.br. 


\section{INTRODUÇÃO}

A alimentação dos animais de companhia passou por uma evolução visível nas últimas décadas. Até a década de 80, a maioria deles ainda era alimentada com restos de comida e existiam poucas indústrias de rações no Brasil. Dois fatores contribuíram para a expansão do segmento: o aumento do poder aquisitivo da população dos grandes centros e a sofisticação dos padrões de consumo. A evolução dos hábitos em favor dos alimentos industriais está associada a um conjunto de fatores cada vez mais difundidos: alimentação sadia e equilibrada, grande variedade de produtos disponíveis no mercado e, principalmente, praticidade (Petbr, 2003).

Normalmente os rótulos das rações para cães trazem valores da composição nutricional mínima (para proteína bruta, extrato etéreo e fósforo) e máxima (para umidade, fibra bruta, matéria mineral e cálcio). Entretanto, não dispõem de dados referentes à digestibilidade e ao valor biológico da proteína. Quando se avalia alimento para cães, os valores da composição nutricional são tão importantes quanto os valores de palatabilidade e digestibilidade. A palatabilidade pode estar ligada à preferência do animal, facilmente detectada pelo proprietário que observa os hábitos do animal. Entretanto, a digestibilidade dos nutrientes contidos na ração requer a intervenção do técnico nutricionista (Holme, 1987; Case et al., 1995).

Um grande problema enfrentado pela indústria de alimentos para animais de estimação está no fator custo e na qualidade da matéria-prima, geralmente mais cara e de difícil obtenção, que se traduz no preço final das rações.

Com relação às fontes alternativas de proteínas, o coeficiente de digestibilidade constitui um fator importante para avaliar seu uso na nutrição animal. Como fontes alternativas, procuram-se alimentos que sejam capazes de fornecer a quantidade de nutrientes necessária para atender às exigências nutricionais dos animais de companhia, com menor custo e sem comprometer sua qualidade, refletindo em produtos mais acessíveis ao consumidor (Silva, 2003).
O objetivo deste trabalho foi avaliar o efeito do processamento sobre a digestibilidade de algumas partes do abate de aves visando à sua utilização como fontes proteicas alternativas na alimentação de animais de companhia, especificamente como alimento para cães.

\section{MATERIAL E MÉTODOS}

O experimento foi realizado no biotério de uma propriedade particular, localizada no município de Viana-ES, em maio e junho de 2005. Foram utilizados 24 cães da raça Terrier Brasileiro, 12 machos e 12 fêmeas, com média de idade de cinco anos e, aproximadamente, $7,5 \mathrm{~kg}$ de peso vivo. Os animais foram alojados individualmente em boxes de $1,60 \mathrm{~m}$ de comprimento por $0,80 \mathrm{~m}$ de largura. Os boxes foram equipados com piso de grade de arame para facilitar a coleta e impedir o contato dos animais com as fezes.

Foram estudados os alimentos, dorso, pés e pescoço de aves, que são partes do abate de frangos de corte obtidas no abatedouro. Os alimentos, testados nas formas crua e cozida, foram inicialmente congelados e moídos em moedor de carne com disco de $3 \mathrm{~mm}$ de diâmetro de furo. A quantidade de cada alimento moído para ser utilizado neste experimento foi de aproximadamente $20 \mathrm{~kg}$. A seguir, cada alimento passou separadamente pelo misturador onde foi adicionado $1 \%$ de sal para melhorar a palatabilidade. Metade do alimento moído, aproximadamente $10 \mathrm{~kg}$, acondicionado em sacos plásticos com aproximadamente $1,5 \mathrm{~kg}$ cada, foi identificado e novamente congelado para ser fornecido como alimento cru. Durante o experimento, o alimento cru foi retirado diariamente do congelador e descongelado por aproximadamente 16 horas, em geladeira, antes de ser fornecido aos animais. A outra metade foi pré-aquecida a $85^{\circ} \mathrm{C}$, enlatada em latas com capacidade de $350 \mathrm{~g}$ e processada em autoclave a $118-121^{\circ} \mathrm{C}$ por uma hora, para que ocorresse o cozimento e a esterilização do produto. Cada alimento, na forma crua ou cozida, foi fornecido a quatro animais, dois machos e duas fêmeas, durante o ensaio de digestibilidade.

O período experimental foi composto por cinco dias de adaptação às condições experimentais e cinco dias de coleta de material como recomendado pela AAFCO (Official..., 2000). 
Os animais, pesados antes e depois do período experimental, foram alimentados uma vez ao dia, com livre acesso ao alimento por um período de uma hora, após o qual os comedouros eram recolhidos e pesados. A quantidade de alimento consumida a cada refeição foi determinada pela diferença do alimento fornecido e do que restou. Durante o período experimental, o alimento foi pesado antes e após o período de consumo e, levando-se em consideração que esses animais necessitam de aproximadamente $70 \mathrm{kcal} / \mathrm{kg}$ de peso vivo/dia, cada animal recebeu, aproximadamente, $50 \mathrm{~g}$ alimento/kg de peso vivo. Para tal, assumiu-se que o valor médio estimado de energia metabolizável dos alimentos era cerca de $1400 \mathrm{kcal} / \mathrm{kg}$. Foram coletadas diariamente e congeladas em sacos plásticos, devidamente identificados, amostras do alimento oferecido para posterior análise.

As fezes foram coletadas diariamente, acondicionadas em sacos plásticos devidamente identificados, pesadas e congeladas a aproximadamente $-4^{\circ} \mathrm{C}$. Após o período de coleta, todo o material armazenado foi descongelado, homogeneizado e pré-seco em estufa ventilada a $60^{\circ} \mathrm{C}$. As análises foram realizadas de acordo com as recomendações da AOAC (Official ..., 1990), para determinação da matéria seca (MS), proteína bruta (PB), extrato etéreo (EE), matéria mineral $(\mathrm{MM})$, cálcio $(\mathrm{Ca})$, fósforo $(\mathrm{P})$ e energia bruta (EB). Os valores de matéria orgânica (MO) foram determinados pela diferença entre a matéria seca e a matéria mineral, tanto dos alimentos como das fezes. A energia metabolizável (EM) foi estimada segundo o modelo indicado pela AAFCO (Official ..., 2000), para conteúdo de energia metabolizável sem coleta de urina:

$\mathrm{EM}(\mathrm{kcal} / \mathrm{kg})=\frac{(\mathrm{a} \times \mathrm{b})-(\mathrm{c} \times \mathrm{d})-\left[\left(\frac{\mathrm{b} \times \mathrm{e}}{100}\right)-\left(\frac{\mathrm{d} \times \mathrm{f}}{100}\right)\right] \times \mathrm{g}}{b} \times 1000$ em que:

a) EB do alimento (Kcal/g); b) total de alimento consumido (g); c) EB nas fezes (Kcal/g); d) peso total de fezes (g); e) \% de PTN no alimento; f) $\%$ de PTN nas fezes; g) fator de correção $(1,25 \mathrm{Kcal} / \mathrm{g})$.

Os coeficientes de digestibilidade aparente (CD) dos nutrientes do alimento foram determinados de acordo com a fórmula indicada por Schneider e Flatt (1975), em que:

$\mathrm{CDA}(\%)=\frac{\text { Nutriente consumido }- \text { Nutriente excretado }}{\text { Nutriente consumido }} \times 100$

O experimento foi realizado em delineamento inteiramente ao acaso. Os dados foram analisados utilizando-se o SAEG (Sistema..., 1997), e as médias de cada alimento separadamente por processamento foram comparadas pelo teste $\mathrm{t}$ a $5 \%$ de probabilidade. Os dados de consumo e variação de peso e de todos os seis alimentos separados pelo tipo de processamento foram submetidos à análise de variância, e as médias comparadas pelo teste SNK a 5\% de probabilidade.

\section{RESULTADOS E DISCUSSÃO}

Os resultados das análises químicas realizadas no pescoço, dorso e pés de aves, crus e cozidos na base da matéria seca, encontram-se na Tab. 1 .

Tabela 1. Valores (\%) da matéria seca (MS), matéria orgânica (MO), proteína bruta (PB), extrato etéreo $(\mathrm{EE})$, matéria mineral $(\mathrm{MM})$, cálcio $(\mathrm{Ca})$ e fósforo $(\mathrm{P})$, e de energia bruta $(\mathrm{EB})(\mathrm{kcal} / \mathrm{kg})$ dos alimentos estudados

\begin{tabular}{llcccccccc}
\hline Alimento & & MS & MO & PB & EE & MM & Ca & P & EB \\
\hline \multirow{2}{*}{ Pescoço } & Cru & 36,46 & 91,61 & 36,20 & 54,19 & 8,39 & 2,42 & 0,61 & 7355,02 \\
& Cozido & 37,63 & 91,58 & 35,00 & 55,11 & 8,42 & 2,00 & 0,68 & 7037,82 \\
\multirow{2}{*}{ Dorso } & Cru & 43,92 & 91,35 & 31,33 & 63,21 & 8,65 & 2,93 & 0,83 & 7003,29 \\
& Cozido & 44,42 & 91,06 & 27,46 & 64,88 & 8,94 & 2,01 & 0,55 & 6748,79 \\
\multirow{2}{*}{ Pé } & Cru & 38,41 & 82,48 & 49,08 & 33,23 & 17,52 & 4,93 & 1,59 & 5796,02 \\
& Cozido & 40,28 & 82,94 & 49,35 & 32,90 & 17,06 & 3,93 & 1,64 & 5769,04 \\
\hline
\end{tabular}


Os pés apresentaram os maiores valores de PB e $\mathrm{MM}$, o pescoço o maior valor de EB e o dorso, os maiores de MS, MO e EE. Os valores de MS e Ca obtidos com o pescoço cru são semelhantes aos obtidos anteriormente, em subprodutos provenientes do mesmo abatedouro, por Dumilho (2003) $)^{1}$, e os de PB, MM e P mais baixos que os relatados pelo mesmo autor, que encontrou $48,6 \%, \quad 15,6 \%$ e $1,1 \%$, respectivamente. $\mathrm{O}$ valor do $\mathrm{EE}$ mais alto que $\mathrm{O}$ encontrado por Dumilho S.A. (Dados de análise de alimentos obtidos no laboratório da Dumilho S.A - Viana, ES), 34,7\%, pode ser atribuído à manutenção da totalidade da pele da região do pescoço, rica em lipídeos, que ocorreu no presente experimento.

Quanto ao dorso cru, os valores de MS, EE e Ca foram mais elevados que os relatados por Dumilho (2003), respectivamente, 35\%, 31,4\% e $2,3 \%$, e os de PB e MM mais baixos, $48,6 \%$ e $13,4 \%$, respectivamente. Murray et al. (1997), ao utilizarem uma mistura de pescoço e dorso de frango crus em experimento com cães, verificaram $38,6 \%$ de MS, 92,9\% de MO, 30,4\% de PB, $50,7 \%$ de EE, $3,4 \%$ de Ca e $0,5 \%$ de P.

O valor da PB para pés crus foi semelhante ao encontrado por Dumilho (2003) de 50\%. Para EE e Ca, foram mais altos que os encontrados pelo mesmo autor, $25,2 \%$ e 4,2\% para EE e Ca, respectivamente, e para $\mathrm{MS}, \mathrm{MM}$ e $\mathrm{P}$, mais baixos, $42 \%, 21,4 \%$ e $1,8 \%$, respectivamente. A variação na composição dos subprodutos de abatedouro de aves estudados na forma crua mostra a desuniformidade de resultados, por isso é desejável maior padronização dos alimentos para se obter melhor resultado, que vise à sua inclusão nas rações de cães.

O cozimento não determinou variações marcantes na composição nutricional dos alimentos estudados, entretanto, de forma geral, os alimentos cozidos, quando comparados aos de forma crua, apresentaram teores mais baixos de PB e mais elevados de EE. Merece destaque a redução aproximada de $12,3 \%$ no valor de $\mathrm{PB}$ do dorso após o cozimento. Observou-se, ainda, redução significativa nos valores de EB do pescoço e do dorso após o cozimento, devendo ser consideradas as reações normais que ocorrem nas diferentes frações da carne durante o processamento. Por outro lado, parte da gordura do alimento cozido tendeu a aderir à superfície da lata, o que dificultou a obtenção de amostras homogêneas e pode ter levado à subestimação da EB.

Os valores do coeficiente de digestibilidade aparente da matéria seca (CDMS), da matéria orgânica (CDMO), da proteína bruta (CDPB), do extrato etéreo (CDEE) e os valores de energia digestível (ED) e energia metabolizável (EM) do pescoço cru e cozido encontram-se na Tab. 2.

Tabela 2. Coeficientes de digestibilidade aparente $(\%)$ da matéria seca (CDMS), da matéria orgânica (CDMO), da proteína bruta (CDPB) e do extrato etéreo (CDEE), e valores de energia digestível (ED) e de energia metabolizável (EM) do pescoço $(\mathrm{kcal} / \mathrm{kg})$ nas formas crua e cozida

\begin{tabular}{lccccccc}
\hline & CDMS & CDMO & CDPB & CDEE & & ED & EM \\
\hline Pescoço cru & $87,40 \mathrm{a}$ & $93,80 \mathrm{~b}$ & $90,00 \mathrm{~b}$ & $98,91 \mathrm{a}$ & & $7019,07 \mathrm{a}$ & $7018,66 \mathrm{a}$ \\
Pescoço cozido & $89,66 \mathrm{a}$ & $95,26 \mathrm{a}$ & $93,50 \mathrm{a}$ & $99,32 \mathrm{a}$ & & $6764,73 \mathrm{~b}$ & $6764,32 \mathrm{~b}$ \\
\hline CV & 2,07 & 0,78 & 1,37 & 0,25 & & 0,67 & 0,67
\end{tabular}

Médias seguidas de letras distintas na coluna diferem entre si pelo teste $\mathrm{t}(\mathrm{P}<0,05)$.

Os coeficientes de digestibilidade aparente da MO e da PB aumentaram significativamente $(\mathrm{P}<0,05)$ quando o pescoço passou pelo processo de cozimento, e os valores de EM e ED diminuíram. As altas temperaturas alcançadas no processamento do alimento, 118 a $121^{\circ} \mathrm{C}$, provocam desnaturação das proteínas e consequente aumento de sua digestibilidade. Por outro lado, não foram observadas diferenças significativas $(\mathrm{P}>0,05)$ nos coeficientes de digestibilidade da MS e do EE.

Os valores do CDMS, CDMO, CDPB e do CDEE e os de ED e EM do dorso cru e cozido encontram-se na Tab. 3. 
Tabela 3. Coeficientes de digestibilidade aparente (\%) da matéria seca (CDMS), da matéria orgânica (CDMO), da proteína bruta (CDPB) e do extrato etéreo (CDEE) e valores de energia digestível (ED) e de energia metabolizável (EM) do dorso ( $\mathrm{kcal} / \mathrm{kg}$ ) nas formas crua e cozida

\begin{tabular}{lllllll}
\hline & CDMS & CDMO & CDPB & CDEE & ED & EM \\
\hline Dorso cru & $89,75 \mathrm{a}$ & $94,75 \mathrm{a}$ & $90,01 \mathrm{a}$ & $99,27 \mathrm{a}$ & $6718,58 \mathrm{a}$ & $6718,23 \mathrm{a}$ \\
Dorso cozido & $91,07 \mathrm{a}$ & $95,56 \mathrm{a}$ & $92,23 \mathrm{a}$ & $99,46 \mathrm{a}$ & $6492,91 \mathrm{~b}$ & $6492,59 \mathrm{~b}$ \\
\hline CV & 1,87 & 0,83 & 2,74 & 0,23 & 0,56 & 0,56
\end{tabular}

Médias seguidas de letras distintas na coluna diferem entre si pelo teste $\mathrm{t}(\mathrm{P}<0,05)$.

Não houve diferença significativa entre os coeficientes de digestibilidade do dorso cru e cozido, porém o cozimento determinou redução significativa da EM e da ED. Os valores de digestibilidade do dorso cru já eram elevados, por isso o cozimento, provavelmente, não propiciou grandes alterações. Entretanto, a leve melhora observada pode justificar o seu cozimento quando presente em rações de cães, associado aos demais subprodutos de abatedouro de aves.

Os valores do CDMS, CDMO, CDPB e CDEE e os de ED e EM dos pés encontram-se na Tab. 4. CDMS, CDMO, CDPB, ED e EM dos pés foram maiores após o cozimento, e CDEE não se alterou com tal procedimento. CDMS, CDMO e CDPB dos pés na forma crua foram mais baixos que os observados para os demais alimentos crus, o que provavelmente explica a melhora significativa $(\mathrm{P}<0,05)$ nos valores de digestibilidade desses nutrientes com o cozimento do alimento. O maior impacto do cozimento foi observado no CDPB $(25,2 \%)$, seguido pelas melhoras no CDMS $(21,8 \%)$, no CDMO $(13,6 \%)$ e no $\operatorname{CDEE}(2,0 \%)$, o que mostra a grande importância de se efetuar um adequado processamento dos alimentos que serão utilizados em rações de cães.

Tabela 4. Coeficientes de digestibilidade aparente (\%) da matéria seca (CDMS), da matéria orgânica (CDMO), da proteína bruta (CDPB) e do extrato etéreo (CDEE), e valores de energia digestível (ED) e energia metabolizável (EM) dos pés $(\mathrm{kcal} / \mathrm{kg})$ nas formas crua e cozida

\begin{tabular}{|c|c|c|c|c|c|c|}
\hline & CDMS & CDMO & CDPB & CDEE & ED & EM \\
\hline Pé cru & $64,67 b$ & $81,70 b$ & $74,82 b$ & $96,82 a$ & $4994,26 b$ & $4993,80 b$ \\
\hline Pé cozido & $78,75 \mathrm{a}$ & $92,79 a$ & $93,70 \mathrm{a}$ & $98,80 \mathrm{a}$ & $5434,84 a$ & $5434,27 \mathrm{a}$ \\
\hline $\mathrm{CV}$ & 4,80 & 1,93 & 2,26 & 1,36 & 1,72 & 1,72 \\
\hline
\end{tabular}

Médias seguidas de letras distintas na coluna diferem entre si pelo teste $\mathrm{t}(\mathrm{P}<0,05)$.

Quanto aos resultados em ED e EM, observouse decréscimo significativo $(\mathrm{P}<0,05)$ com $\mathrm{O}$ cozimento dos alimentos pescoço e dorso, o que provavelmente foi devido aos menores valores de EB determinados para esses alimentos cozidos, como descrito anteriormente. Os valores de ED e EM dos pés cozidos foram maiores $(\mathrm{P}<0,05)$ que os dos pés na forma crua, o que pode estar relacionado à melhora geral na digestibilidade da MO.

Os valores de EM dos alimentos testados tanto em sua forma crua quanto na cozida foram muito próximos aos da ED. Isto pode ser atribuído ao fato de que todos os alimentos apresentaram CDEB muito elevados, em média 94\%. Também foram elevados os teores de PB e, como cada alimento foi fornecido para um grupo de cães como única fonte de alimento, os animais acabaram ingerindo grandes quantidades de um nutriente com alto coeficiente de digestibilidade. Os cães, no período experimental, ingeriram grande quantidade de $\mathrm{PB}$ e, provavelmente, excretaram maior quantidade de nitrogênio que o normal, por isso o uso do mesmo fator de correção para o cálculo do conteúdo de EM em todos os grupos, técnica utilizada para determinação da EM sem coleta de urina, pode ter subestimado o cálculo de excreção de nitrogênio pela urina e superestimado o valor em EM do alimento, especialmente nos grupos que apresentaram maior perda de peso. Na prática, a maior parte 
das rações oferecidas aos animais de companhia apresenta, em média, 18\% de PB.

A variação de peso corporal dos cães, o consumo dos alimentos estudados no período experimental e a ingestão diária de EM são apresentados na Tab. 5.

Não foram observadas diferenças significativas $(\mathrm{P}>0,05)$ nas características peso corporal, consumo do alimento e ingestão diária de EM, o que, provavelmente, está relacionado ao alto valor do coeficiente de variação $(\mathrm{CV})$ dos dados. Altos valores de CV são frequentemente encontrados em experimentos com cães, devido principalmente à impossibilidade de se obter animais uniformes quanto ao sexo, idade, tamanho, peso corporal e comportamento. A escolha da raça também merece destaque, uma vez que a raça pode determinar o padrão de comportamento animal. Neste trabalho, utilizaram-se cães da raça Terrier Brasileiro, animais que costumam ser extremamente agitados, o que dificultou alguns procedimentos como a pesagem e a coleta de fezes. Valores altos de CV em experimentos com cães foram também observados por Silva (2003). Os animais que receberam pés cozidos e pescoço cru foram os únicos que apresentaram algum ganho de peso ao final dos cinco dias de adaptação e dos cinco dias de coleta.

Tabela 5. Variação de peso dos animais (período de 10 dias) e consumo do alimento e ingestão diária de energia metabolizável (EM) no período experimental (5 dias)

\begin{tabular}{|c|c|c|c|}
\hline Alimento & Variação de peso & $\begin{array}{l}\text { Consumo de } \\
\text { alimento } \\
\end{array}$ & $\begin{array}{c}\text { Ingestão diária de } \\
\text { EM }\end{array}$ \\
\hline & $\mathrm{kg}$ & $\mathrm{kg}$ & kcal \\
\hline Pescoço cru & $0,100 \mathrm{a}$ & $1,565 \mathrm{a}$ & $800,83 a$ \\
\hline Pescoço cozido & $-0,200 a$ & $1,571 \mathrm{a}$ & $799,88 \mathrm{a}$ \\
\hline Dorso cru & $-0,275 a$ & $1,287 \mathrm{a}$ & $759,16 a$ \\
\hline Dorso cozido & $-0,025 a$ & $1,476 \mathrm{a}$ & $851,50 \mathrm{a}$ \\
\hline Pé cru & $-0,175 a$ & $1,797 \mathrm{a}$ & $689,39 a$ \\
\hline Pé cozido & $0,350 \mathrm{a}$ & $1,556 \mathrm{a}$ & $681,19 a$ \\
\hline Média & $-0,038$ & 1,542 & 763,66 \\
\hline $\mathrm{CV}$ & $-1606,008$ & 26,864 & 25,341 \\
\hline
\end{tabular}

Não foram observadas diferenças (teste $\mathrm{SNK}-\mathrm{P}>0,05$ ).

Os animais que consumiram pés cozidos apresentaram aumento de peso, média de $350 \mathrm{~g}$, e os que consumiram pescoço na forma crua ganharam, em média, apenas $100 \mathrm{~g}$. Os cães que consumiram dorso e pés na forma crua e pescoço e dorso cozidos terminaram o período experimental com perdas de peso corporal. Esses resultados não podem ser explicados pelos conteúdos energéticos dos alimentos, uma vez que o pescoço na forma crua apresentou valores maiores em EB, ED e EM do que os pés cozidos. Vale ressaltar que todos os alimentos estudados continham valores energéticos relativamente altos e que as variações no peso corporal foram, provavelmente, devido ao estresse experimental e às deficiências nutricionais do alimento ingerido, Visto que, para o atendimento das exigências diárias dos cães, é necessária a ingestão de uma mistura ou ração balanceada.

\section{CONCLUSÕES}

É possível a inclusão de todos os ingredientes estudados nas rações de cães, desde que considerados os seus reais valores nutricionais. O cozimento melhora, de forma significativa, a digestibilidade dos pés e do pescoço.

\section{REFERÊNCIAS BIBLIOGRÁFICAS}

CASE, L.P.; CAREY, D.P.; HIRAKAWA, D.A. (Eds). Canine and Feline Nutrition: A resource for companion animal professionals. St. Louis: Mosby, 1995. 455p.

HOLME, D.W. Alimentos para cães e gatos. In: EDNEY, A.T.B. (Ed). Nutrição do cão e do gato: um manual para estudantes, veterinários, criadores e proprietários. São Paulo: Manole, 1987. p.37-51 
MURRAY, S.M.; PATIL, A.R.; FAHEY, G.C. et al. Raw and rendered animal by-products as ingredients in dog diets. J. Anim. Sci., v.75, 24972505, 1997.

OFFICIAL methods of Analysis. Washington, DC: Association of Official Analitical Chemists, 1990.

OFFICIAL publication. Atlanta: Association of American Feed Control Officials, 2000.

PETBR, A Força dos nutrientes. Disponível em: <http://www.petbrasil.com.br>, Acessado em 20 mai. 2003.

SCHNEIDER, B.H.; FLATT, W.P. The evaluation of feeds through digestibility experiments. Athens: University Georgia, 1975. 423p.
SILVA, W.V. Avaliação de digestibilidade $e$ valores energéticos de alguns ingredientes para rações de cães (Canis familiaris). 2003. 40f. Dissertação (Mestrado em Zootecnia) Universidade Federal Rural do Rio de Janeiro, Seropédica, RJ.

SISTEMA de análises estatísticas e genéticas SAEG. Viçosa:UFV, 1997. 